\title{
The Integral Approach to Safety
}

\author{
${ }^{1}$ Dzulqarnain Bin Abu Bakar \& ${ }^{2}$ Norazura Binti Ismail \\ ${ }^{1,2}$ Faculty of Engineering Technology, University Malaysia Pahang, 26300, Kuantan, Pahang, Malaysia \\ Ihyperbaricperson@gmail.com
}

\begin{abstract}
There is a need to balance the reliance on a traditional OSHMS being implicitly adhered to against the human contribution factor. The aim of this qualitative study paper is to describe and discuss the existing leadership styles and approaches that are being practiced and past initiatives that have produced results in OSH performance. The snowball sampling review method of literature published between years 1997 through 2016 was applied to produce the observations and discussion. Despite the progress that is being realized, there needs to be a different approach if a sustainable performance breakthrough in OSH performance is to be achieved. The integral approach leans towards transformational leadership style and attempts to acknowledge that the subjective and objective, personal and collective factors are all equally important towards establishing wholesome and robust OSHMS. Traditional reliance on discipline and rule-based compliance needs to be tempered with an interdependent realization and awareness from the individual carrying out a task that they are ultimately responsible for their safety. Leadership and management will then need to take on the role and challenge of providing support and resources to enable the development of this self-accountable culture.
\end{abstract}

Index Terms: Integral approach, subjective side of safety, safety culture, OSHMS evolution.

\section{INTRODUCTION}

This paper asserts that there needs to exist a balance between the subjective and objective views towards occupational safety practices and approaches at the workplace. The transformational safety leadership-consulting firm of JMJ Associates (2009) advocates that safety culture evolves from a dependent stage to an independent stage then proceeds onwards to an interdependent stage. This concept is not isolated from Hudson's (2007) development model that suggests safety evolution occurring through three waves, which are the technical wave, the system wave and the cultural wave.

Glendon et al.[1] offer a different school of thought where it is suggested that the each period of development does not leave behind the preceding period, but rather it builds on what has been achieved before. This developmental stage is referred to as the fourth stage of safety or the 'integration age'. In this stage, the previous thoughts and leanings are not lost but are integrated and remain available to be reflected upon as the individual perspectives as well as the organizational dynamics continue to evolve.

Without discounting Glendon et al. (2006) suggestion on the integration age, it would be appropriate to introduce the next, or the fifth level of evolution, which could be termed as the integral age'. The integral age encompasses the past stages of development and integrates them into future plans and actions without discounting the past learning. It is not merely an accumulation of learning but an efficiency-thoroughness trade off (ETTO). It is also resilience engineering as described by Holnagell [2]. This is essentially moving away from the contemporary view and traditional application of occupational safety and health management system (OSHMS) being the end-all guiding document providing answers to safety rules and safety development. 


\section{THE HUMAN INTERFACE IN OSHMS}

There is an increasing body of literature that point towards the fallacy of over reliance on, and in many cases, the sole reliance of a documented OSHMS in addressing risk management. Robson et al. [3] carried out an extensive review of health and safety management system and concluded, "there is insufficient evidence in the published, peer-reviewed literature on the effectiveness of OSHMS to make recommendations either in favor of or against OSHMSs". This is similar to the view detailed in the 1999 Report of the Longford Royal Commission into the explosion at the Esso Longford gas plant in Victoria. Among the findings of the investigation team was that although Esso had a world-class OSHMS, in reality the system had mutated into something that it was not designed for. It was "divorced from operations in the field" and thus "diverting attention away from what was actually happening in the practical functioning of the plants in Longford" [4].

The Gretly Mine disaster which occurred in 1996 and as analyzed by Hopkins [5] shared the same observation that "experience is now teaching us that safety management systems are not enough to ensure safety". In support of this view, the New South Wales Mines Advisory Council advocates in a report commissioned in 2007 that the OSHMS should be developed based on a principle of mindfulness and not be one that is "complex, paper-based OSH management system".

Reason [6] holds a view that managers view culture as being separate from OSHMS. This is based on the observation that an over reliance of OSHMS while having an underdeveloped appreciation and understanding of the workplace culture can cause failure, because "it is the workplace culture that ultimately determines the success or failure of such systems".

Hopkins [7] argues that safety culture has become a major focus towards improving OSH performance mainly stemming from the realization that there are limitations to OSHMS. The dangers of having culture of silos, culture of rules and culture of on-time running along with a risk-denying or risk-blind were some of the cultural aspects highlighted by Hopkins in his interpretation of the 1999 Glenbrook train crash between a commuter train and the Indian Pacific. These are issues that are not addressed by traditional OSHMS's and are often only clearly visible or noted after an incident has occurred or in hindsight.

Hopkins (2007) also believes that safety culture is only one element of an organizational culture, or rather the one element that focuses on safety. Therefore, to adjust and adapt the safety culture will require the adaptation of the collective group and not only of individuals. Efforts to change culture will need the focus of changing collective practices (practices of both the managers and workers). This view is heavily based on Reason's [8] work that promotes a safe culture being an informed culture supported with Weick and Suttcliffe's $(2001 ; 2007)$ elaboration on collective mindfulness.

The argument from Reason (1997) is that engineering or creating a safety culture can be done and that a safe culture is an informed culture. His argument is that in addressing the situation of facing risk and what is the acceptable risk threshold, organizations need to aim for maximum resistance to risk. This aim for maximum resistance to risk needs to be clearly distinguished between the now clichéd 'zero risk' slogan being touted excessively.

Towards establishing a balance between the operational practicalities of managing safety based on an OSHMS while developing an integral approach towards leadership in general, JMJ Associates (2009) have suggested the application of a conceptual mental-model adapted from the work of Wilber (2000). Within this conceptual integral approach model, the organization is viewed holistically from 4 quadrants described as interior (subjective) and exterior (objective) point of view by individuals and groups.

JMJ Associates (2009) adopts a view based on the model propounded by Wilber (2000) that a fundamental approach to creating safety performance breakthrough is to explore both the subjective and objective, personal and collective factors, which influence choice and behavior. This is based on the premise that collective individuals make up an organization, thus creating a group. From a metasystem point of view, these collective factors can be translated as, a) The unique way that an individual views the situation. For example: "I believe that management cares for my safety"; b) The way a group views the situation- the collective understanding, beliefs and commitments. For example: "We are committed to being the industry leader in safety performance"; c) The view of something 
(including a person or behavior from the outside. For example: "He should have used his gloves for that task." and d) The view of group of things from the outside. For example: "I see that they carry out housekeeping after each task is completed".

A point to note is that the initial two points- namely (a) and (b) as described above is not visible from the outside or it does not manifest itself to an observer. These are referred to as the subjective view or internal perspective. The latter two points of view on the other hand infer the view of perspective that can be observed or seen from the outside. These are referred to as the objective view or external perspective (JMJ Associates, 2009). When viewed as a whole, the integral approach can be depicted as the four-quadrant map that informs or provides insight to supplement the reliability and efficiency of an existing OSHMS.

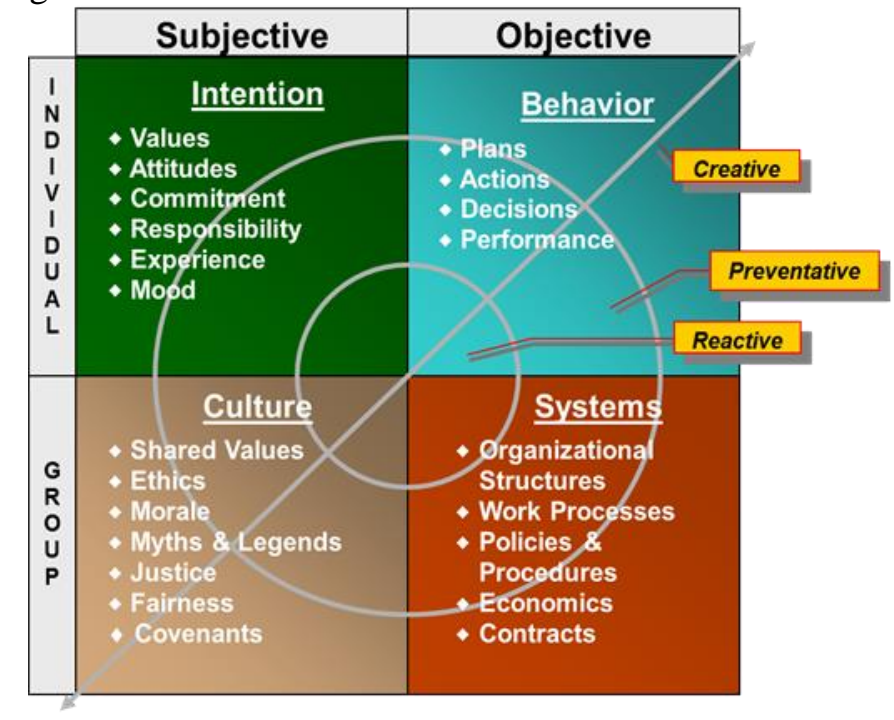

Figure 1. The integral perspective (as developed by JMJ Associates and adapted from Ken Wilber's Four Quadrant model)

Based on the adaptive leadership concept developed by Heifetz (1994), JMJ Associates (2009) further asserts that by insisting on the validity of all perspective presented in the integral approach and their dynamic interrelationship, this four-quadrant map allows for a robust and compounded understanding of safety performance. This understanding in turn ensures that the critical, if not all, factors related to a task or assignment are considered prior to any action being planned or undertaken.

Danner [9] at the 2012 National Safety Council Congress and Expo elaborated on organizational safety culture being the manifestation of mindset, belief and values. This culture can be measured in part by applying the DuPont Bradley Curve to demonstrate the progressive maturity of the organizations culture (DuPont, 2012). The reactive, dependent, independent and interdependent phases are similar in concept to the reacting, conforming, achieving and integral phases applied by JMJ Associates (2009) in their safety consulting practice.

DuPont's (2012) view on the four phases is as follows,

(i) Reactive: In this phase, safety is led by natural instincts; changes often are not made until incidents occur and senior leadership or management are not closely involved in the process.

(ii) (ii) Dependent: This phase has management commitment, rules and procedures, and employees are held accountable and receive safety training and discipline, but it is a command and control type of culture. 
(iii) Independent: Workers in this phase value safety as individuals. They think about their safety in regards to whatever they are doing individually. Individuals in this phase care for themselves and their own safety and feel personal value.

(iv) Interdependent: Workers in this final phase go beyond caring about their own safety and instead feel invested in others' safety, as well. There is no hierarchy when it comes to safety because everyone is concerned about it. For example, a janitor might point out a safety oversight or provide input on a safety related performance enhancement process to an operations manager, and the manager will not feel slighted, but rather, the manager would be grateful that this employee is invested in safety over and above the job-scope boundary. This is a caring and concerned teamwork-centered environment that goes beyond behavior-based safety culture that may merely be paper-based safety at times.

\section{MOVING AWAY FROM BLIND OSHMS COMPLIANCE AND MOVING TOWARDS AN INTERDEPENDENT MINDSET.}

Conventional thinking based on experience dictates that safety rules written for the benefit of the workforce safety can be scripted with enough details and thus will serve to meet legal and other industry code requirements. There are now emerging views that more rules does not necessarily equate to better safety results, and these views are backed with findings and statistical data. Reason (1997) noted that there are times when writing more rules can contradict the action required to complete the task. Hopkins (2005) promotes the act of complementing safety rules with a risk assessment process that invites the workers to not only comply with rules in a mindless fashion, but to also understand the intricacies of why the control measures are in place.

Hale et al. (2003), Jeffcott et al. (2006) and Deker (2003) stressed the need for organizations to understand the gap between procedure and practice instead of simply increasing pressure to comply. This would contribute towards developing operator's skill at adapting his responses in any given unusual situation or any departure from the normal standard operating procedures. .

Dekker (2003) goes on to propose the following for organizations to pay attention to:

a) Monitor the gap between procedure and practice and try to understand why it exist (and resist trying to close it by simply telling people to comply).

b) Help people to develop the skill to judge when \& how to adapt (and resist telling people they should follow procedures)

The description above is summarized by the term "Collective Mindfulness," that variability in human performance can enhance safety mindfulness while unvarying performance can undermine safety, particularly in a complex socio-technical systems.

Hopkins (2007) in his analysis of the Gretley mine disaster and Hopkins (2001) Esso Longford gas plant in Victoria was critical of managers not being mindful and points out the need for leaders to be mindful as a prerequisite to avoid disaster. In a further analysis of the BP (British Petroleum) Texas City explosion, Hopkins [10] reviewed how BP had set their sights on being a High Reliability Organization (HRO) insomuch as to display characteristics of collective mindfulness. This attempt was not entirely successful as the focus was mainly on training the front line workers, but without much attention paid to the organizational elements that needed to be present in an organization to support the development of collective mindfulness.

Learning from failures contrasted against celebrating success, as well as strong response to weak signals are among the traits of HRO as described by Weick et.al (1999). HRO's are described to be 'complex, adaptive systems by Weick et.al (1999) because they are 'preoccupied with failure' and treat any lapse as 'something wrong with the system'; that they are 'reluctant to simplify' and attempt to simplify less and see more. They are also 'sensitive to operations' and promote situation awareness for crewmembers at the sharp end. They have 'a commitment to resilience' and refuse to allow errors to disable them. 
Reason (2008) has argued that towards "maintaining a state of intelligent wariness", then both individual mindfulness and collective mindfulness is necessary. This view represents a view that is moving away from the view that collective mindfulness takes precedence over individual mindfulness as propounded by Weick and Hopkins. Reason (2008) holds the view that individual mindfulness is paramount by asking the following question: "If we cannot make systems immune to organizational accidents, what can we do to improve the reliability and wisdom of those at the sharp end?"

The sharp end in this context refers to a person who is directly interacting with the hazard at a given time under a given context. Essentially, these people are the last line of defense between safe execution and unsafe incident outcome. Giving these people (people at the sharp end) the knowledge and skills of recognizing when to adapt is good for safety performance when it could be lifethreatening.

\section{CONCLUSION}

The value of having a robust OSHMS is undeniable, and has been proven to be the foundation of many HRO, yielding incremental improvements in safety performance. Along with this acknowledgement of success, and as surfaced by this paper, there is a realization that strictly relying on safety rules to control or manipulate behaviors has it evident limitations. The more mature and high-risk workforce are now slowly but steadily morphing towards the integral approach to safety. This is an age where the previous phases of being reactive, conforming and achieving are transcended by an integral phase. This essentially means that there are no cultural-progression-developmental elements that are replaced or removed, but rather, the future managers and leaders are working within the previous phase's boundaries and building on them with the ultimate aim of future improvements.

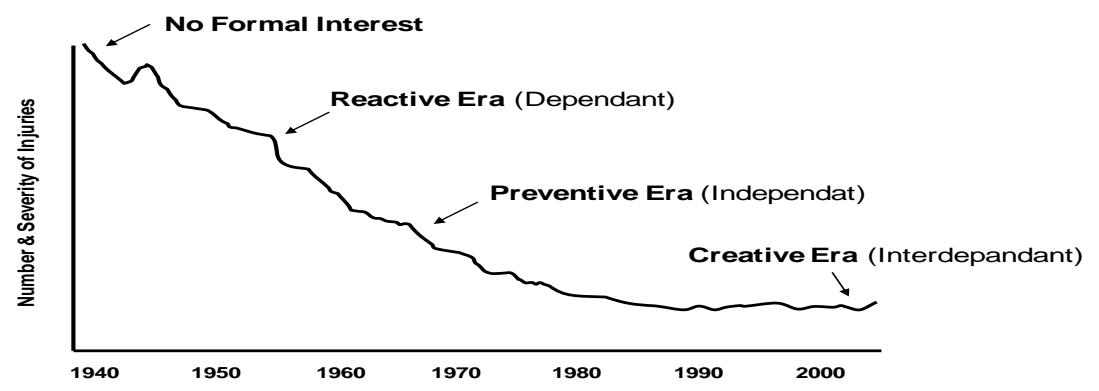

Figure: 2. The Stages of Safety Evolution. Adapted from: JMJ Associates (1997)

The integral approach to safety acknowledges that there exists socially constructed subculture within a traditional OSHMS within an organization. Within this realization is imbedded the adaptive culture and resilience engineering, and to understand and begin to use this technology, human variability needs to be acknowledged an accepted as an asset important for safety.

It is also the starting point towards analyzing what specific actions that can be initiated, or should be stopped towards establishing a proactive safety culture. It is envisioned that these specific actions will be the potential focus areas for the authors' future research activities.

\section{REFERENCES}

[1] Glendon, A.I, Clarke, S.G \& McKenna, E.F. Human safety and risk management.( $2^{\text {nd }}$ Ed). Boca Raton, FL. (2006). 
[2] Hollnagel, E. The ETTO principle. Surrey, England: Ashgate. (2009a).

[3] Robson, L., Clarke, J., Cullen, K., Bielecky, A., Severin, C., Bigelow, P., et al. The effectiveness of occupational health and safety management systems: A systematic review. Toronto, Ontario: Institute for Work \& Health. (2005).

[4] Dawson, D.M., \& Brooks, B.J. The Esso Longford gas plant accident: Report of the Longford Royal Comission. Melbourne, Vic: Parliament of Victoria. (1999).

[5] Hopkins, A. Lessons from Gretley: Mindful leadership and the law. Sydney: CCH Australia. (2007).

[6] Reason, J. Beyond the limitations of safety systems. Australian Safety News, April, 54-55. (2000).

[7] Hopkins, A. Safety, culture and risk. Sydney: CCH Australia. (2005).

[8] Reason, J. Managing the risks of organizational accidents. Aldershot: Ashgate. (1997).

[9] Danner, R. National Safety Council Congress and Expo, Orlando, Florida. (2012).

[10] Hopkins, A. Failure to learn: The BP Texas City refinery disaster. Sydney: CCH. (2008). 